\title{
Um novo nome em Conyza (Asteraceae - Astereae)
}

\author{
Aristônio M. Teles ${ }^{1,2}$ \& João Renato Stehmann ${ }^{1}$
}

\section{Resumo}

(Um novo nome em Conyza (Asteraceae - Astereae)) Um novo nome é proposto para a tribo Astereae (Asteraceae) no Brasil: Conyza neolaxiflora A. Teles \& Stehmann (sinônimo: Erigeron laxiflorus Baker, não Conyza laxiflora Desf.), assim como é discutida a afinidade com Conyza monorchis (Griseb.) Cabrera, espécie morfologicamente relacionada.

Palavras-chave: Brasil, Compositae, Conyzinae, Erigeron, nomenclatura.

\section{Abstract}

(A new name for Conyza (Asteraceae - Astereae)) A new name is proposed for the tribe Astereae (Asteraceae) in Brazil: Conyza neolaxiflora A. Teles \& Stehmann (synoym: Erigeron laxiflorus Baker, not Conyza laxiflora Desf.), and a discussion of its relationship with the closely related Conyza monorchis (Griseb.) Cabrera is presented.

Key words: Brazil, Compositae, Conyzinae, Erigeron, nomenclature.

\section{INTRODUÇÃO}

O gênero Conyza Less. pertence à subtribo Conyzinae e compreende entre 60 e 100 espécies (Bremer 1994; Nesom 1994; Nesom \& Robinson 2007), distribuídas em áreas tropicais e subtropicais (Nesom \& Robinson 2007). Conyzinae é uma tribo composta por oito gêneros (Nesom \& Robinson 2007), dos quais metade possui espécies com distribuição restrita à América do Sul (Noyes 2000).

Baker (1882) citou oito espécies brasileiras de Conyza. Cronquist (1943) propôs novos caracteres para a separação de Conyza e Erigeron L., baseado neste estudo e transferiu as espécies de Erigeron seção Caenotus para Conyza, com a exceção de uma espécie, Erigeron laxiflorus Baker, possivelmente pelo fato de não ter visto nenhum dos síntipos da mesma, que se encontram depositados no Herbário de Kew (K) (acrônimo segundo Holmgren 1990). Posteriormente, Cabrera (1959 e 1972) descreveu novas espécies de Conyza ocorrentes no Brasil. Lourteig \& Cuatrecasas (1985) e Pruski \& Sancho (2006) propuseram novas combinações para o gênero, aumentando consideravelmente o número de espécies registradas no Brasil. Durante a preparação da sinopse das espécies brasileiras da tribo Astereae, constatamos a necessidade de transferir Erigeron laxiflorus para o gênero Conyza, baseado nos caracteres morfológicos utilizados por Cronquist (1943) e por Nesom \& Robinson (2007), sobretudo pela presença de flores pistiladas com corola filiforme ou brevemente ligulada ( $v s$. flores pistiladas com lígula bastante desenvolvida de Erigeron). Além dos caracteres morfológicos já mencionados, Cronquist (1943), Noyes (2000) e Teles et al. (2008) comentam que as espécies de Erigeron possuem distribuição restrita à América do Norte e Central, e que as espécies sul-americanas, originalmente descritas em Erigeron, são atualmente pertencentes a outros gêneros da subtribo Conyzinae. Entretanto, pelo fato de o epíteto específico utilizado por Baker (1882) já ter sido utilizado por Desfontaines para uma espécie de Conyza descrita para a França (Conyza laxiflora Desf.) constatamos a necessidade de ser propor um novo nome para a espécie.

Levando-se em conta esses aspectos propomos o seguinte novo nome:

\footnotetext{
Artigo recebido em 12/2007. Aceito para publicação em 04/2008.

${ }^{1}$ Universidade Federal de Minas Gerais, Instituto de Ciências Biológicas, Departamento de Botânica, Av. Antônio Carlos 6627, Pampulha, 31270-910, Belo Horizonte, Minas Gerais, Brasil.

${ }^{2}$ Autor para correspondência: aristonio@ hotmail.com
} 
Conyza neolaxiflora A. Teles \& Stehmann, nom. nov.

Erigeron laxiflorus Baker, Fl. bras. 6(3): 31. 1882. Tipo: BRASIL. SÃO PAULO: S. Bernardo, Burchell 3955 (lectótipo K, aqui designado), não Conyza laxiflora Desf., Tabl. École Bot. (ed. 2) 400. 1829.

Material adicional examinado: BRASIL. SÃO PAULO: Morumbi, Burchell 4481 (K, síntipo, visto fotografia).

Conyza neolaxiflora é morfologicamente afim a $C$. monorchis (Griseb.) Cabrera, mas difere pelo indumento glabro a subglabro, pela capitulescência corimboso-paniculada e pela ausência de raízes tuberiformes (vs. indumento hirsuto, capitulescência corimbiforme e raiz tuberosa). Com a nova combinação aqui proposta, o gênero Conyza passa a ser representado no Brasil por 13 espécies e duas variedades.

Baker (1882) citou três síntipos, Burchell 3955 (designado aqui como lectótipo), Burchell 4481 e Sello 832, e indicou que viu apenas os materiais de Burchell. O material coletado por Sello não possui designação de localidade. No síntipo Burchell (4481) consta uma pequena nota manuscrita indicando que a exsicata é igual ao material coletado por Sello (832).

\section{Agradecimentos}

Gostaríamos de externar os nossos agradecimentos ao Dr. D. J. Nicholas Hind (Royal Botanic Gardens, Kew) pelo envio das imagens dos síntipos. ACAPES pela bolsa de doutorado, e ao $\mathrm{CNPq}$ pela bolsa de produtividade em pesquisa, bolsas essas fornecidas ao primeiro e ao segundo autores, respectivamente.

\section{REFERÊNCIAS BIBLIOGRÁFICAS}

Baker, J. G. 1882. Compositae: Asteroidae, Inuloideae. In: Martius, C. F. P. von \&
Eichler, A. G. Flora brasiliensis. Munchen, Wien, Leipzig 6(3): 1-134.

Bremer, K. 1994. Asteraceae: cladistics and classification. Timber Press, Portland, 752p.

Cabrera, A. L. 1959. Compositae catarinensis novae. Boletín de la Sociedad Argentina de Botânica 7(3-4): 187-200.

1972. Tres nuevas especies del genero Conyza (Compositae) del noroeste de la Argentina. Boletin de la Sociedad Argentina de Botanica 14(4): 347-353.

Cronquist, A. 1943. The separation of Erigeron from Conyza. Bulletin of the Torrey Botanical Club 70: 629-632.

Holmgren, P. K.; Holmgren, N. H. \& Barnett, L. C. 1990. Index herbariorum. Part. I: The herbaria of the world. New York Botanical Garden, New York.

Lourteig, A. \& Cuatrecasas, J. 1985. Nomenclatura plantarum Americanum III. Compositae. Phytologia 58(7): 475-476.

Nesom, G. L. 1994. Subtribal classification of the Astereae (Asteraceae). Phytologia 76(3): 193-274.

\& Robinson, H. 2007. XI. The tribe Astereae Cass. (1819). In: Kadereit, J. W. \& Jeffrey, C. The families and genera of vascular plants. Berlin, Springer. 8: 284-342.

Noyes, R. D. 2000. Biogeographical and evolutionary insights on Erigeron and allies (Asteraceae) from ITS sequence data. Plant Systematics and Evolution 220: 93-114.

Pruski, J. F. \& Sancho, G. 2006. Conyza sumatrensis var. leiotheca (Compositae: Astereae), a new combination for a common neotropical weed. Novon 16: 96-101.

Teles, A. M., Sobral, M. \& Stehmann, J. R. 2008. Synopsis of Leptostelma (Asteraceae: Astereae). Compositae Newsletter 46: 1-6. 